[Regular Paper]

\title{
Defect Reconstruction of Submarine Oil Pipeline from MFL Signals Using Genetic Simulated Annealing Algorithm
}

\author{
Wenhua HAN* and Peiwen Que \\ Dept. of Information Measurement Technology and Instruments, Shanghai Jiaotong University, \\ No. 800 Dongchuan Road, 200240, Shanghai, P. R. CHINA
}

(Received October 17, 2005)

\begin{abstract}
This paper presents a genetic simulated annealing algorithm (GSAA)-based inverse algorithm for reconstructing the shape of a two-dimensional defect from the magnetic flux leakage (MFL) signals. In the algorithm, the GSAA formulated by incorporating the simulated annealing technique into the mutation operator of the standard genetic algorithm (GA) is employed to solve the optimization problem in the inverse problem, and a radial-basis function neural network (RBFNN) is utilized as the forward model. Experimental results demonstrated that the GSAA-based inverse algorithm is more accurate and is more robust to noise than the GA-based inverse algorithm.
\end{abstract}

\section{Keywords}

Oil pipeline, Defect reconstruction, Genetic algorithm, Simulated annealing, Inverse problem

\section{Introduction}

The magnetic flux leakage (MFL) method is now established as the most widely used in-line inspection technique for the evaluation of submarine oil pipelines. Inverse problems in MFL nondestructive evaluation (NDE) involve determining the defect parameters such as the length, width, or defect shape based on the information contained in the measured signals. Inverse problems are commonly solved using iterative methods ${ }^{1)}$. These methods involve solving well-behaved forward problem in a feedback loop. Conventionally, numerical models such as the finite-element model (FEM) are to represent the forward process. However, iterative methods using the numerical-based forward models are computationally expensive. Neural networks are utilized for solving inverse problems in $\mathrm{NDE}^{1) \sim 4)}$ and used to represent the forward process in the iterative methods ${ }^{1)}$. The advantages of using neural networks are that neural networks can approximate any arbitrary function and can be trained off-line. Hwang et al. ${ }^{3)}$ described the use of a wavelet basis function (WBF) neural network to predict three-dimensional defect profiles. Ramuhalli et al. ${ }^{4)}$ used two neural networks in feedback configurations. In this method, a forward network is used as the forward model, and an inverse network is used to predict the profile given the measured MFL signals. Ramuhalli et al. ${ }^{1)}$ proposed a

\footnotetext{
* To whom correspondence should be addressed.

* E-mail: hanwenhua@sjtu.edu.cn
}

neural-network-based iterative inversion algorithm using neural networks as a forward model. In the algorithm, the problem of defect profile reconstruction from MFL signals is formulated as an optimization problem, where the defect profile is updated using a combination of gradient descent and simulated annealing to minimize the error between the measured signal and the model predicted signal. Arkadan et al. introduced a genetic algorithm based approach for crack identification $^{5)}$. Li et al. presented a genetic local search (GLS) algorithm for reconstructing the profiles of 3-D defects from eddy-current NDE signals ${ }^{6}$.

This paper presents a genetic simulated annealing algorithm (GSAA)-based inverse algorithm for 2-D defect reconstruction from MFL signals. In the algorithm, a radial-basis function neural network (RBFNN) is utilized as forward model, and the GSAA which is formulated by incorporating the simulated annealing technique into the mutation operator of the genetic algorithm is used to solve the optimization problem in the inverse problem. Experimental results show that the GSAA-based inverse algorithm is more accurate and is more robust to noise than the GA-based inverse algorithm.

\section{Development of Genetic Simulated Annealing Algorithm}

The genetic algorithm (GA) is a search mechanism based on the principles of natural selection and population genetics and has been widely applied in a number 
of different areas ${ }^{7), 8)}$. Instead of a point-by-point search, the GA offers a parallel search of the solution space rather than a single region. Hence, the GA can find a near global optimal solution and consequently avoid the local minimum solution possibly encountered in the gradient-descent-based optimization approach. A canonical GA usually begins with a randomly generated set of potential solutions, called the initial population. Each member in the population represents a possible solution of the problem. A fitness function is used as a measure of the closeness of each member in the population to the global optimum solution. Then, members from the population are selected to produce new members, called descendents or children, by applying stochastic operators to the selected members. The selection mechanism often favors the highly fit members in such a way that the members more close to the global optimal solution are assigned higher probabilities for producing children. The most common genetic operators are crossover and mutation. A crossover operator combines the features presented in parents to produce descendents. Crossover methods include single-point crossover, two-point crossover and uniform crossover. A mutation operator slightly perturbs a selected member in a random manner. Typical mutation methods include Gaussian mutation ${ }^{9)}$ and uniform mutation. A new generation is then formed using the descendents to replace part or all of the members in the current population. Crossover operations ensure that the new population inherits highly fit features while mutation operations may add previously unexploited features into the population. It is hoped that in doing so, the population would, very likely, drift to a global or near global solution after a number of generations. This search process is called genetic evolution. Genetic algorithm based optimization approaches involve consideration of five key issues: parameter representation, measure of the fitness of potential solutions, an initial population, genetic operators to update the population, and termination criterion.

The simple canonical GA may be trapped by local optima or converge prematurely when solving the optimum of large-scale combinatorial optimization problems. The performance of canonical GA can be improved by introducing more diversity among the members in the early stage of the solution process so that the premature convergence can be prevented. In order to avoid premature convergence, the genetic local search (GLS) algorithm ${ }^{6)}$ casts the simulated annealing method into the frame of the canonical GA, and the genetic annealing algorithm $(\mathrm{GAA})^{10)}$ incorporates the probabilistic acceptance test technique of simulated annealing into the incremental genetic algorithm (IGA). Premature convergence can also be prevented by using mutation operators with various mutation rates or mutation ranges ${ }^{9) \sim 13)}$. This study developed GSAA by in- corporating the simulated annealing technique into the mutation operator of the canonical GA. In a similar way to the $\mathrm{GAA}^{10)}$, the simulated annealing technique is used to control the variance for Gaussian mutation in the GSAA. The member to be mutated is perturbed according to the Gaussian probabilistic distribution function (GPDF) with its variance controlled by the simulated annealing technique. The perturbation of the $i$ th component of the selected member can be written as

$$
x_{i}^{\prime}=x_{i} \pm \Delta x_{i}
$$

where $\Delta x_{i}$ is the amount of perturbation on the $x_{i}$. Using the simulated annealing technique, the amount of perturbation can be expressed as

$\Delta x_{i}=\left(x_{i \max }-x_{i \min }\right) \cdot T_{k} \cdot \operatorname{randn}(0,1)$

where $\operatorname{randn}(0,1)$ is a Gaussian random number with zero mean and unit variance, $x_{i \max }$ and $x_{i \min }$ denote the extreme values of $x_{i}$ in the search space, and $T_{k}$ is the temperature of the $k$ th generation and is reduced according to the following equation:

$$
T_{k}=r^{(k-1)} T_{0}
$$

where $T_{0}$ is the initial temperature, and $r$ is the temperature reduction factor. It should be noted that the Gaussian mutation with the simulated annealing technique reduces to the conventional Gaussian mutation when $r=1$. Since the perturbation is centered on the original value of $x_{i}$, smaller perturbation implies a more local search, whereas larger perturbation is better for introducing diversity. Equation (2) shows that the amount of perturbation is regulated and reduced as the evolution process progresses.

The GSAA can be summarized as follows.

(1) Randomly build an initial population.

(2) Create a sequence of new populations, or generations. At each step, the algorithm uses the individuals in the current generation to create the next generation. To create the new generation, the algorithm performs the following steps:

a. Score each member of the current population by computing its fitness value.

b. Scale the raw fitness scores to convert them into a more usable range of values.

c. Select parents based on their fitness using a roulette wheel selection method.

d. Produce children from the parents. Children are produced by performing uniform crossover and by performing Gaussian mutation with simulated annealing technique which is used to control the variance of the Gaussian mutation.

e. Replace the current population with the children to form the next generation.

(3) The algorithm stops when the stopping criterion is met. The average fitness value of the population is used as the stopping criterion. The algorithm stops when the average fitness value of the population is greater than a predefined threshold. Otherwise, return 


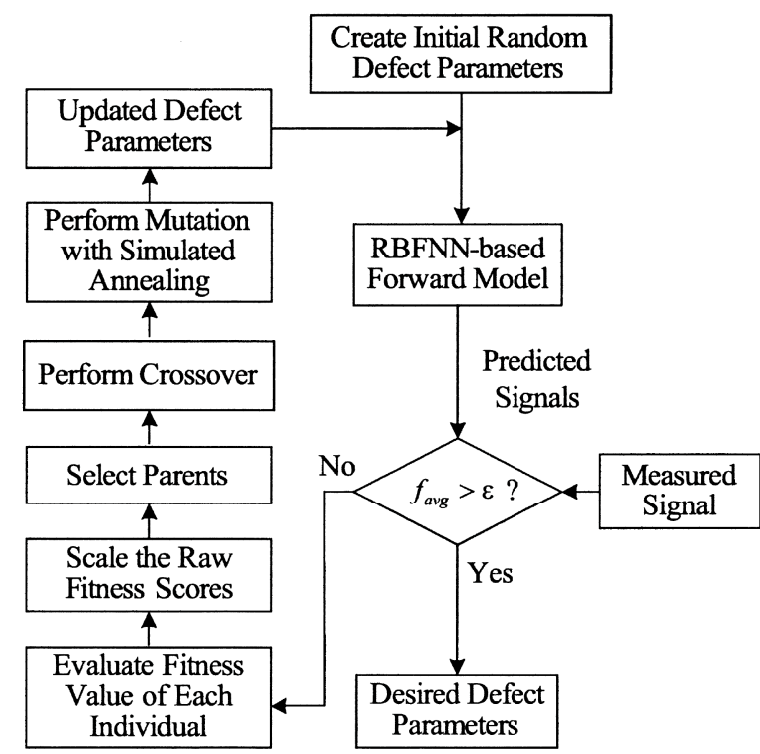

Fig. 1 Block Diagram of the GSAA-based Inverse Algorithm

to Step 2 .

\section{GSAA-based Signal Inverse Algorithm}

Figure 1 shows the block diagram of the GSAAbased inverse algorithm. In this approach, the radialbasis function neural network (RBFNN) ${ }^{14)}$ is used to model the forward process and the GSAA described above is used to solve the optimization problem in the iterative process. The procedure begins with a set of randomly created initial defect parameters. The RBFNN forward model is used to predict the signals corresponding to these defect parameters. These predicted signals are then compared to the measured signal and the corresponding value of the fitness function is computed. If the average fitness value $f_{\text {ivg }}$ is greater than a predefined threshold $\varepsilon$, the iterative process is terminated. Otherwise, genetic operators are employed to update the defect parameters in the current defect parameter set. This algorithm stops until the termination criterion is met, and the fittest defect shape in the last iterative process is then viewed as the optimal defect shape corresponding to the measured signal.

The radial-basis function neural network (RBFNN) is used to model the forward process to predict the MFL signal $\boldsymbol{y}=\left(y_{1}, y_{2}, \cdots, y_{M}\right)$ associated with the defect shape $\boldsymbol{x}=\left(x_{1}, x_{2}, \cdots, x_{N}\right)$, where $N$ is the number of defect parameters and $M$ is the dimension of the output. The defect parameter $x_{i}$ and the corresponding signal $y_{i}$ are presented to the input and output layer nodes. The I/O relation for the RBFNN using Gaussian-basis functions is given by ${ }^{1)}$

$$
\begin{aligned}
& y_{l}=\sum_{j=1}^{H} w_{l j} \exp \left(-\frac{\left\|\boldsymbol{x}-\boldsymbol{c}_{j}\right\|^{2}}{2 \sigma_{j}^{2}}\right) \\
& j=1,2, \cdots, H, \quad l=1,2, \cdots, M
\end{aligned}
$$

where $H$ is the total number of basis functions used, $w l j$ are the expansion coefficients or weights associated with each basis function, $\boldsymbol{c}_{j}$ is the center of the $j$ th Gaussian-basis function, and $\sigma_{j}$ is the width of the Gaussian function. The orthogonal least squares learning algorithm provides a simple and efficient means for fitting radial basis neural networks ${ }^{15}$.

A cost function is defined as the sum-squared error between the desired measured signal $\boldsymbol{d}=\left(d_{1}, d_{2}, \cdots, d_{M}\right)$ and the actual predicted output $\boldsymbol{y}=\left(y_{1}, y_{2}, \cdots, y_{M}\right)$ of the neural network and is computed as

$$
E=\sum_{i=1}^{M}\left(d_{i}-y_{i}\right)^{2}
$$

In a similar way to the method of Yue et l $^{6}{ }^{6}$, the minimization of the above cost function is recast as maximizing the following fitness function:

$$
f=\frac{1}{1+C \sum_{i=1}^{M}\left(d_{i}-y_{i}\right)^{2}}
$$

where $C$ is a constant. The maximum value of the fitness function is 1.0. The constant $C$ controls the relative ration between the global maximum and local maxima. It can be seen that $0<f \leq 1$.

As a result, the defect reconstruction problem can be viewed as an optimization problem, which seeks defect parameters to maximize the fitness function. The optimization problem is solved using the ICGA described above.

For the specific 2-D defect reconstruction problem in this study, a candidate solution is represented by the defect shape $\boldsymbol{x}=(w, d)$, where $w$ and $d$ are the width and depth of the defect, respectively. As the values of defect parameters are continuous, real values are used to represent each defect parameter.

The inverse algorithm where the optimization problem is solved using the canonical GA is referred to as the GA-based inverse algorithm.

\section{Experimental Results}

Experiments are presented to verify the effectiveness of the GSAA-based inverse algorithm and to compare it with the GA-based inverse algorithm. The MFL data are generated by means of a 2-D finite element model (FEM), and only the cross section of the defect with varying widths and depths is modeled. A set of 240 defects was used to generate the corresponding MFL signals. The defects varied in width from 1 to 7 inch and depth from 0.15 to 0.85 inch in a sample of unit thickness. As described in the technical paper by 
Table 1 Results Comparing the Performance of the GSAA-based and GA-based Inverse Algorithms for a Defect (2.6 inch width, 0.60 inch (60\%) depth)

\begin{tabular}{|c|c|c|c|c|c|c|c|}
\hline \multicolumn{4}{|c|}{ GA } & \multicolumn{4}{|c|}{ GSAA } \\
\hline $\begin{array}{l}\text { Width } \\
\text { [inch] }\end{array}$ & $\begin{array}{c}\text { Depth } \\
{[\%]}\end{array}$ & $G$ & $E$ & $\begin{array}{l}\text { Width } \\
\text { [inch] }\end{array}$ & $\begin{array}{c}\text { Depth } \\
{[\%]}\end{array}$ & $G$ & $E$ \\
\hline 2.4542 & 60.0772 & 12 & $4.10 \mathrm{E}-05$ & 2.6116 & 59.9912 & 14 & $1.70 \mathrm{E}-06$ \\
\hline 2.5915 & 60.0588 & 7 & $1.53 \mathrm{E}-06$ & 2.6553 & 59.8454 & 8 & $8.73 \mathrm{E}-06$ \\
\hline 2.6737 & 60.0127 & 8 & $1.18 \mathrm{E}-05$ & 2.5883 & 60.0044 & 12 & $1.60 \mathrm{E}-06$ \\
\hline 2.6095 & 64.5363 & 9 & $1.56 \mathrm{E}-04$ & 2.5648 & 60.1461 & 6 & $7.15 \mathrm{E}-06$ \\
\hline 2.6011 & 60.0316 & 8 & $1.39 \mathrm{E}-06$ & 2.5244 & 60.1404 & 8 & $1.57 \mathrm{E}-05$ \\
\hline 2.5823 & 59.9807 & 10 & $1.90 \mathrm{E}-06$ & 2.6554 & 60.0536 & 11 & $7.09 \mathrm{E}-06$ \\
\hline 2.5296 & 65.4508 & 14 & $1.37 \mathrm{E}-04$ & 2.6015 & 60.0583 & 8 & $1.40 \mathrm{E}-06$ \\
\hline 2.6183 & 59.7621 & 11 & $2.11 \mathrm{E}-05$ & 2.6021 & 60.0004 & 11 & $1.42 \mathrm{E}-06$ \\
\hline 2.7329 & 54.9535 & 4 & $1.70 \mathrm{E}-04$ & 2.6100 & 60.0754 & 10 & $1.63 \mathrm{E}-06$ \\
\hline 2.5390 & 60.1466 & 12 & $1.23 \mathrm{E}-05$ & 2.5415 & 60.0988 & 11 & $8.62 \mathrm{E}-06$ \\
\hline
\end{tabular}

Table 2 Results Comparing the Performance of the GSAA-based and GA-based Inverse Algorithms for Defects with Various Width and Depth Parameters

\begin{tabular}{|c|c|c|c|c|c|c|c|c|c|}
\hline \multicolumn{2}{|c|}{ True parameters } & \multicolumn{4}{|c|}{ GA } & \multicolumn{4}{|c|}{ GSAA } \\
\hline $\begin{array}{l}\text { Width } \\
\text { [inch] }\end{array}$ & $\begin{array}{c}\text { Depth } \\
{[\%]}\end{array}$ & $\begin{array}{l}\text { Width } \\
\text { [inch] }\end{array}$ & $\begin{array}{c}\text { Depth } \\
{[\%]}\end{array}$ & $G$ & $E$ & $\begin{array}{l}\text { Width } \\
\text { [inch] }\end{array}$ & $\begin{array}{c}\text { Depth } \\
{[\%]}\end{array}$ & $G$ & $E$ \\
\hline 1.8 & 35 & 1.73 & 35.23 & 12 & $1.61 \mathrm{E}-05$ & 1.79 & 35.00 & 7 & $1.43 \mathrm{E}-06$ \\
\hline 1.8 & 80 & 1.83 & 80.05 & 9 & $1.05 \mathrm{E}-05$ & 1.79 & 80.00 & 6 & $3.91 \mathrm{E}-06$ \\
\hline 2.2 & 60 & 2.16 & 59.95 & 11 & $5.05 \mathrm{E}-06$ & 2.23 & 60.05 & 10 & $6.38 \mathrm{E}-06$ \\
\hline 2.6 & 50 & 2.54 & 49.94 & 7 & 7.47E-06 & 2.63 & 50.09 & 7 & $3.49 \mathrm{E}-06$ \\
\hline 3.0 & 60 & 2.95 & 60.01 & 12 & $9.71 \mathrm{E}-06$ & 3.02 & 59.95 & 8 & $5.00 \mathrm{E}-06$ \\
\hline 3.4 & 60 & 3.29 & 59.92 & 9 & $2.76 \mathrm{E}-05$ & 3.41 & 59.95 & 13 & $1.57 \mathrm{E}-06$ \\
\hline 4.2 & 35 & 4.18 & 34.75 & 9 & $1.64 \mathrm{E}-05$ & 4.16 & 34.89 & 11 & $3.22 \mathrm{E}-06$ \\
\hline 5.0 & 35 & 4.94 & 35.06 & 11 & 4.16E-06 & 4.96 & 35.03 & 10 & $3.28 \mathrm{E}-06$ \\
\hline 5.4 & 75 & 5.43 & 74.71 & 11 & $1.33 \mathrm{E}-04$ & 5.40 & 75.05 & 10 & $3.21 \mathrm{E}-06$ \\
\hline
\end{tabular}

Ramuhalli et al. ${ }^{1)}$, of these 240 defect shape-MFL signal pairs, 210 were used to train the neural networks while 30 were used as part of the test database with no overlap between the training and test sets. The radialbasis function neural network (RBFNN) is trained using the orthogonal least squares learning algorithm ${ }^{15}$. In GA and GSAA, the real value is used to represent the member in the population, uniform crossover and Gaussian mutation are used, and an initial population of size 300 is built randomly. The parameters in Eq. (3) used in the GSAA are set as $T_{0}=1$ and $r=0.9$.

Table 1 shows the results of 10 independent trials for 2.6 inch width, 0.60 inch $(60 \%)$ deep defect comparing the performance of the GSAA-based and GAbased inverse algorithms. In the Table 1, $G$ represents the number of generations required for the convergence of the algorithms, and $E$ represents the value of the cost function defined by Eq. (5) after the convergence of the algorithms. It can be seen that the GSAA-based inverse algorithm reaches the global optimum for all 10 trials, whereas the GA-based inverse algorithm is trapped in local optima for some trials. In addition, the GSAA-based inverse algorithm is more accurate than the GA-based inverse algorithm.

Table 2 shows the results comparing the perfor- mance of the GSAA-based and GA-based inverse algorithms for defects with various width and depth parameters. It can be seen that the GSAA-based inverse algorithm reaches all various defects, whereas the GAbased inverse algorithm is trapped in local optima for some defects. In addition, the GSAA-based inverse algorithm is more accurate than the GA-based inverse algorithm.

In fact, the signals to be inverted are usually corrupted with additive white Gaussian noise. The noise level is described by the signal-to-noise ratio (SNR), which is defined as SNR $=10 \log \left(P_{\mathrm{s}} / \sigma^{2}\right)$ where $P_{\mathrm{s}}$ and $\sigma^{2}$ are signal power and noise power, respectively. Table 3 shows the results of GSAA-based and GA-based inverse algorithms for a 3.0 inch width, 0.60 inch (60\%) deep defect using noisy signals with different SNR. These results indicate that the GSAA-based inverse algorithm is more robust to noise than the GA-based inverse algorithm.

The above results show that the GSAA-based inverse algorithm can accurately reconstruct the defect parameters and exhibits better performance than the GA-based inverse algorithm. 
Table 3 Results Comparing the Performance of the GSAA-based and GA-based Inverse Algorithms for a Defect (3.0 inch width, 0.60 inch deep) with Noise

\begin{tabular}{|c|c|c|c|c|c|c|c|c|}
\hline \multirow[b]{2}{*}{$\begin{array}{l}\text { SNR } \\
{[\mathrm{dB}]}\end{array}$} & \multicolumn{4}{|c|}{ GA } & \multicolumn{4}{|c|}{ GSAA } \\
\hline & $\begin{array}{l}\text { Width } \\
\text { [inch] }\end{array}$ & $\begin{array}{c}\text { Depth } \\
{[\%]}\end{array}$ & $G$ & $E$ & $\begin{array}{l}\text { Width } \\
\text { [inch] }\end{array}$ & $\begin{array}{c}\text { Depth } \\
{[\%]}\end{array}$ & $G$ & $E$ \\
\hline 45 & 3.0566 & 59.9853 & 8 & $9.58 \mathrm{E}-06$ & 3.0201 & 60.0441 & 10 & $4.84 \mathrm{E}-06$ \\
\hline 40 & 3.0165 & 60.2636 & 9 & 4.63E-05 & 3.0211 & 59.9578 & 6 & 4.88E-06 \\
\hline 35 & 2.8499 & 60.1154 & 8 & $5.79 \mathrm{E}-05$ & 2.9851 & 60.0462 & 10 & $5.30 \mathrm{E}-06$ \\
\hline 30 & 3.1143 & 59.7069 & 8 & $7.30 \mathrm{E}-05$ & 2.9716 & 59.8472 & 8 & $1.48 \mathrm{E}-05$ \\
\hline 25 & 2.9919 & 59.7125 & 7 & $6.54 \mathrm{E}-05$ & 3.0101 & 59.9958 & 17 & $4.21 \mathrm{E}-06$ \\
\hline 20 & 3.0808 & 59.7612 & 4 & 3.79E-05 & 2.9978 & 60.0339 & 7 & $4.41 \mathrm{E}-06$ \\
\hline 15 & 2.8850 & 64.6577 & 9 & $1.49 \mathrm{E}-04$ & 2.9637 & 60.0486 & 16 & 8.03E-06 \\
\hline 10 & 3.0471 & 60.2002 & 6 & $2.12 \mathrm{E}-05$ & 2.9968 & 59.8536 & 7 & $1.07 \mathrm{E}-05$ \\
\hline
\end{tabular}

\section{Conclusions}

A GSAA-based inverse algorithm is proposed for 2-D defect reconstruction of submarine oil pipelines from MFL signals, where the GSAA is formulated by incorporating the simulated annealing technique into the mutation operator of the canonical genetic algorithm. In the proposed inverse algorithm, a radial-basis function neural network (RBFNN) is utilized as the forward model, and the GSAA is used to solve the optimization problem in the inverse problem. The GSAA can prevent the premature convergence of the canonical GA and improve the performance of the canonical GA by incorporating the simulated annealing technique into the mutation operator of the canonical GA. Experimental results have demonstrated that the GSAA-based inverse algorithm can accurately reconstruct the defect parameters, exhibits better performance and is more robust to noise in the MFL signals than the GA-based inverse algorithm.

\section{Acknowledgments}

The authors thank Associate Professor Pradeep Ramuhalli and Professor Lalita Udpa in the Department of Electrical and Computer Engineering at Michigan State University, East Lansing for providing the MFL data set.

\section{References}

1) Ramuhalli, P., Udpa, L., Udpa, S. S., IEEE Transactions on Magnetics, 38, (6), 3633 (2002).

2) Lim, J., D. Thesis, Iowa State University, Iowa, USA, 2001.

3) Hwang, K., Mandayam, S., Udpa, S. S., Udpa, L., Lord, W., Atzal, M., NDT \& E International, 33, (8), 531 (2000).

4) Ramuhalli, P., Udpa, L., Udpa, S. S., J. Applied Physics, 93, (103), 8274 (2003)

5) Arkadan, A. A., Sareen, T., Subramaniam, S., IEEE Transactions on Magnetics, 30, (6), 4320 (1994).

6) Yue, Li, Udpa, L., Udpa, S. S., IEEE Transactions on Magnetics, 40, (2), 410 (2004).

7) Goldberg, D. E., "Genetic Algorithms in Search, Optimization \& Machine Learning," Addison-Wesley, (1989).

8) Srinivas, M., Patnaik, L. M., Computer, 27, (6), 17 (1994).

9) Hinterding, R., IEEE International Conference on Evolutionary Computation, Perth, WA, 1995, 1, p. 384.

10) Wong, K. P., Wong, Y. W., IEE Proceedings-Generation, Transmission and Distribution, 141, (5), 507 (1994).

11) Srinivas, M., Patnaik, L. M., IEEE Transactions on Systems, Man and Cybernetics, 24, (4), 656 (1994).

12) Boeringer, D. W., Werner, D. H., Electronics Lett., 38, (25), 1618 (2002).

13) Sareni, B., Krahenbuhl, L., Nicolas, A., IEEE Transactions on Magnetics, 36, (4), 1027 (2000).

14) Haykin, S., "Neural Networks: A Comprehensive Foundation," Englewood Cliffs, NJ: Prentice-hall, (1994).

15) Chen, S., Cowan, C. F. N., Grant, P. M., IEEE Transactions on Neural Networks, 2, (2), 302 (1991). 
要旨

遺伝的焼きなましアルゴリズム手法による送油パイプライン磁束漏洩信号からの瑕疪部形状の再現

\section{Wenhua Han, Peiwen Que}

Dept. of Information Measurement Technology and Instruments, Shanghai Jiaotong University,

No. 800 Dongchuan Road, 200240, Shanghai, P. R. CHINA

遺伝的アルゴリズムに焼きなまし法を組み入れ，初期におい て高く出現する突然変異率を徐々に低くしていく手法である遺 伝的焼きなましアルゴリズム（GSAA）法は最適化手法の一つ としてよく知られており, さまざまな分野において応用されて いる。また，同手法は単なる遺伝的アルゴリズム手法よりもそ の精度は優れており, 雑信号の多いデー夕から有用な信号のみ
を抽出する場合に強みを発揮するといわれている。本論文にお いては海底送油用パイプラインの瑕疪の検査法として広く利用 されている手法である磁束漏洩非破壊検査法の信号処理への GSAA 法の適用性を実験結果に基づき検討した上で，精度よく 種々の瑕疪パラメーターを再現することが可能であるとの結論 を導き出している。 